\title{
Visualization as assemblage
}

\section{Exploring critical visualization practice ${ }^{1}$}

\section{Keywords: actor-network theory, assemblage} theory, critical practice, mapping, social advocacy, information visualization

The Anti-Eviction Mapping Project is an example of critical visualization practice that interrogates both its own conditions of production and how who is represented is also affected by the representations. In order to describe and analyze this form of practice the notion of assemblage as well as tools from actor-network theory are employed. These concepts allow the researcher or designer to consider how visualizations operate beyond its existence as a discrete representation but rather as a process that weaves a network of humans and non-humans together which is especially relevant to a critical engagement in information visualization practice.

\section{Introduction}

Over the past decade thousands of families have been evicted from dwellings in downtown San Francisco to make room for investment properties that serve techcompany employees. These families-predominantly poor, immigrant, and racialized-continue to be displaced in order to fuel an officially endorsed creative economy.
This displacement is an example of a wider ongoing phenomenon in which sectors of society are both made invisible and discarded because of a paradoxical combination of their status as a perceived threat to economic or societal stability, as well as their vulnerability and alterity. Part of what allows for this dynamic to continue is the relative invisibility of the processes that either exacerbate risks, displace families, or obfuscate accountability.

The Anti-Eviction Mapping Project (AEMP) provides an example of how information visualization, mapping and community organizing form a visualization assemblage that can help to counter the effects, and potentially some of the causes, of gentrification and displacement. Moreover, this particular form of visualization assemblage constitutes a critical visualization practice that prioritizes the ethical ways that people and things are represented.

\section{Networks and assemblages}

The principal motifs in this analysis, network and assemblage, are drawn from both the sociology of science and technology, as well as post-structuralist theory, respectively. In particular, sociologist Bruno Latour's actor-network theory $(A N T)^{2}$ approach and theorists Gilles Deleuze and Felix Guattari's assemblage ${ }^{3}$ approach 
provide a complimentary set of concepts useful in the description and analysis of what information visualizations are and how they function. Networks prioritize the relational character of entities. Assemblages, the term that will be used more often, denotes both this relational character but emphasizes the constant process of assembling. In addition, assemblages allow us to think beyond the discreet characteristics and instead attend to the relational and material character of things. In other words, things are both assemblages of other things and processes as well as part of other assemblages.

A strength and potential weakness of these two approaches is in how they both focus on the associations between human and non-human nodes which, in turn, requires an acknowledgement that non-humans have agency-that is, they can affect other non-humans and humans. The advantage this gives the researcher or designer is the ability to broaden the scope of entities that are included in the analysis thus making the work richer and more comprehensive. The disadvantage is the lack of a stabilized set of methods and concepts that can consistently describe phenomena across all these registers and that meets conventional standards of academic rigour. Nevertheless, I believe that this disadvantage is outweighed by the advantage and provides the opportunity to create a valuable analytical as well as synthetic outcome. This is in part due to where the two approaches differ in their respective mode-a network approach emphasizes the tracing of the exact character of the intermediations between things and people and associations, while an assemblage approach emphasizes the mapping of potential connections. Martin Müller underscores this difference by suggesting that "one way to think of ANT is as an empirical sister-in-arms of the more philosophical assemblage thinking" (2015: 30). Combining the network and the assemblage therefore allows for a more nuanced tool to examine processes such as the AEMP project which produces visualizations, organizes humans, and produces feeling.

Under the rubric of ANT, Latour has developed several concepts that help us describe and understand how knowledge is produced and reproduced. Of particular interest to our current project are the concepts: interessement, matters of concern, immutable mobiles and cascades of inscriptions. These tools can be imbricated to show how a particular process of visualization could: incorporate human participants and translate their knowledge into a stabilized form (interessement); assemble a network of human and material components in order to promote a specific description of a phenomenon (matter of concern); allow a textual/visual description of a phenomenon travel time and space relatively unchanged (immutable mobile); and articulate a set of textual-visual representations such that they increase their claim on truth (cascade of inscriptions). Deleuze and Guattari developed an assemblage theory from which we can draw on the concept that an assemblage can: ground itself in a concrete context (territorialization); move and reproduce itself in other contexts (de- and reterritorialization); and determine how material components or human participants are framed and interpreted (enunciation and expression).

These concepts help frame information visualizations and maps as both assemblages and parts of assemblages in such as way that it reveals how participants are brought into visualizations and how visualizations are used by people, simultaneously. For instance, the AEMP offers an example of how a visualization assemblage both incorporates participants and disseminates representations through events, performances, interfaces, and maps-which themselves constitute a set of linked assemblages $^{4}$. I will focus on a few interrelated AEMP projects to show how networks and assemblages are formed and how they can be deployed in acts of resistance. 


\section{Expressing a matter of concern}

$A E M P$ is an attempt to make visible a matter of concern. It can be seen as a network of actors and as an assemblage that expresses. It does this by visually representing the pattern of displacement of tenants, and re-presenting the voices and desires of the displaced tenants and activists.

The notion of a matter of concern (Latour 2004) attempts to encapsulate the dynamics between different assemblages that work towards establishing the ontological status of a given issue. The matter of concern, in this case, is essentially the gentrification of San Francisco, which involves the displacement of tenants-many of whom are lower-income, people of colour, and recently arrived immigrants. While the municipality represents the revitalization and real estate investment in the area as a positive development for the city's wellbeing, the AEMP represents the externalized human costs of this development.

A central factor in this practice is the Ellis Act, a provision that according to many critics has been systematically abused by property owners and developers to evict low-rent tenants in order to bring in high-paying tenants. This has resulted in a $75 \%$ increase in evictions in two years. AEMP refers to these Ellis Act evictions as no-fault evictions. They are the key variable that is plotted in many of AEMP's interactive maps.

The Ellis Act interactive maps, which are also often shown as animated timelines, depict the rise and spread of evictions by property owners ostensibly moving into the building (see Figure 1). The user can click on the play button in order to start the timeline animation, which shows a chronological sequence of evictions from 1997 to 2014, totalling 3,775 families evicted. Each eviction is represented by an exploding marker which alludes to the devastation a bombing run might have had on a city in World War II. The visualization has a rhetorical force that is easy to detect-with each impact shown on the map the number of families affected increases. When more families are evicted at once, the explosion is proportionately greater.

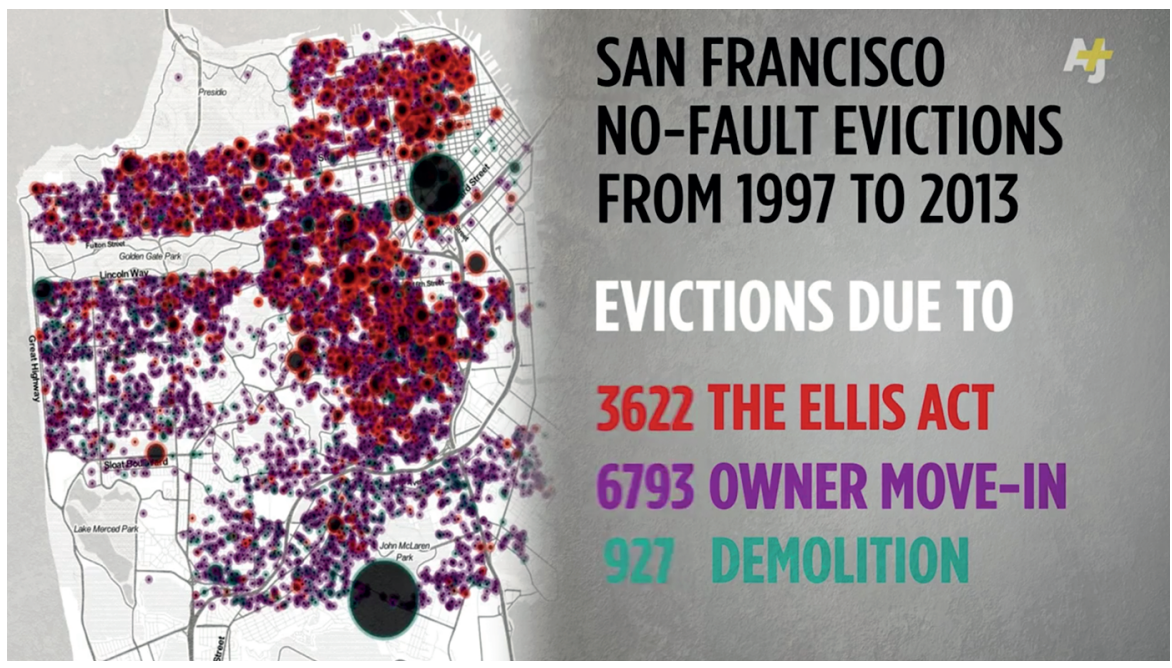

Figure 1. Interactive map (screen capture). From “Ellis Act Evictions" by Anti-Eviction Mapping Project (n.d.-a). 
In addition to the website and their social media presence (e.g., AEMP's Facebook page has almost 11,156 followers and approximately 2,579 Twitter followers as of August 15, 2015), the AEMP has also used the local, national, and international news media to its advantage by being covered in over 200 separate news stories in just over 14 months. One of these stories by $\mathrm{AJ}+$ takes the form of a 32-second YouTube video that repackages an $A E M P$ (no-fault eviction timeline) map visualization by animating it along with titles, captions, and a soundtrack (AJ+, 2014) (see Figure 2). This treatment of the original Ellis Act Eviction Map further augments the rhetorical force of the visualization by dramatizing the human dimension of the issue and adding a sense of urgency with a sombre yet rhythmically driving soundtrack.

This adaptation of the original eviction map illustrates how visualizations are circulated and repackaged through growing social networks and content producers. Data-driven visualizations and compelling illustrations of dramatic changes over time prove to be highly-valued content for media organizations-AEMP has both.

The AEMP currently has two versions of this mapone detailing the occurrences in San Francisco and the other in Santa Monica. Using the same design (i.e., visual style, format, mapping cloud-service, and code) AEMP, in collaboration with the Pico Neighborhood Association and Rent Control Board of Santa Monica, has created

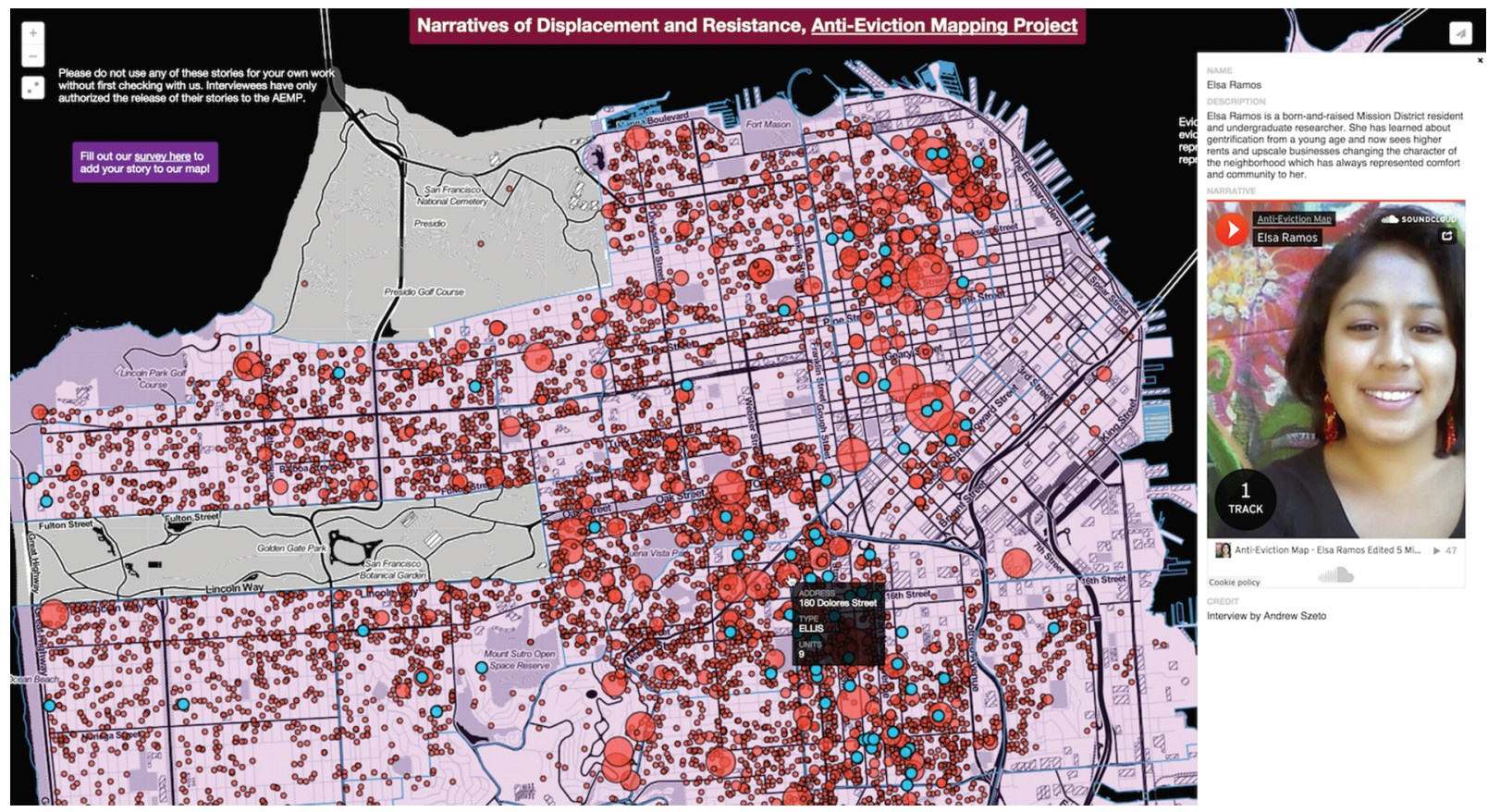

Figure 2. Reproduction of AEMP Ellis Act Evictions map as a video (screen capture). From “Mapping San Francisco's No-Fault Evictions Since 1997" by AJ+ (2014). 
a map that shows the same issue that is plaguing San Francisco occurring in other parts of California.

In both the evictions maps (e.g., San Francisco and Santa Monica) and in the AJ+ news clip we can observe a fairly consistent visual style which has added impact each time it has been used. But the visual surface of the map speaks only to one dimension of the power of the visualization to travel across different registers. The other dimension is the data itself, which has been recombined with other data sets to bring out a related insight through the representation of patterns that draw initial and potentially alarming correlations.

To illustrate this correlation AEMP created the No-Fault Evictions and Tech Bus Stops map (AntiEviction Mapping Project 2013). AEMP used Stamen Design's (2012) The City from the Valley project as a basis to create a map with two important layers: markers showing Tech Bus Stops and areas with high numbers of evictions. This combination demonstrates an apparent correlation between the location of bus stops and the higher rate of evictions. On the website they offer an analysis which states that " $69 \%$ of No-Fault Evictions each year occurred within four blocks of known shuttle stops" (Anti-Eviction Mapping Project, n.d.). This would suggest that the evictions are an effect of the high desirability of well-heeled tech employees to property owners who exploit no-fault evictions designed to evacuate buildings for renovation, and then offer the improved units at higher prices.

This use of the maps suggests that it is important to consider the power of how visualizations can travel from one context to another and how they can be reassembled and reconfigured with other data. Although Latour's (1990) notion of immutable mobiles ${ }^{5}$ is extremely useful in understanding the cognitive, representational, and administrative capacities of visualizations, it is less useful when considering the work of $A E M P$, even if we select just one map and trace its trajectory. This is because the
San Francisco map and data are re-used in a number of ways (e.g., YouTube videos, murals, other maps, oral history maps). The map is therefore multi-sensory, multi-dimensional, multi-platform, or multi-media. Its mutability is precisely the feature that allows AEMP to flesh out an issue and reach a diverse range of users and viewers. For instance, the same issue of Ellis Act evictions is documented in San Francisco and in Santa Monica. By using the same design and inserting the data and information specific to the municipality, $A E M P$ increases the strength of the argument against these displacements.

This is also somewhat different from Latour's (2010) concept of the cascade of inscriptions which entails a series of related or allied diagrams, maps, reports, etc. that strengthen the veridical value of the visualization. Similar to how the cascade involves a process of building a fact, the maps/data of the AEMP also attempt to stabilize their concern into a fact. But the difference lies in how it is not a procession of inscriptions of which any specific visualization can be a part but rather a multiplicity of visualizations. It is, instead, expressive. It entails a variety of non-linear outcomes of a mapping process. At times, it resembles a previous map, as in the case of the AJ+ video, because of the data used. At other times, it resembles the style of a previous map but the data and the location are different, as in the case of the Santa Monica map. At still other times, the map is expressed in completely other forms including media and kinds of embodiment.

The power of this expressivity is evidenced in how the $A E M P$ uses its suite of maps to present the different strengths of quantitative and qualitative data. For instance, $A E M P$ uses data analysis and visualization along with the human voice to retell the experience of community and dispossession. We see the same data now assembled with recordings and images of residents 
and survivors. While the technical process is a relatively straightforward layering of data (i.e., eviction data with geo-located audio files) the result represents an expressive transformation of form: the evicted tenants are represented in the eviction maps, and some of these same tenants are represented through their stories. Using Deleuze and Guattari's (2004) notion of expression we can see that while the content (i.e., the tenants) remains the same, the forms of expression proliferate (e.g., dots on a map and voices in your ear). A further expansion of the concept of expression and its relation to the process of incorporating participants into a project is discussed in the next two sections.

\section{From interessement to assemblage}

Like the Ellis Act Eviction Maps, the Narratives of Displacement Oral History Map plots the number of no-fault evictions through the use of circle area markers on a standard Mercator-style projection map of the city area. This quickly shows the magnitude and expanse of displacements in the San Francisco Bay Area (SFBA) over the past several years when they have soared alongside real estate speculation. It also shows the increasing influx of tech startups and big tech company (e.g., Google, Salesforce) employees to the surrounding area (see Figure 3). Unlike the eviction maps discussed above, this map shows all the evictions over the past two
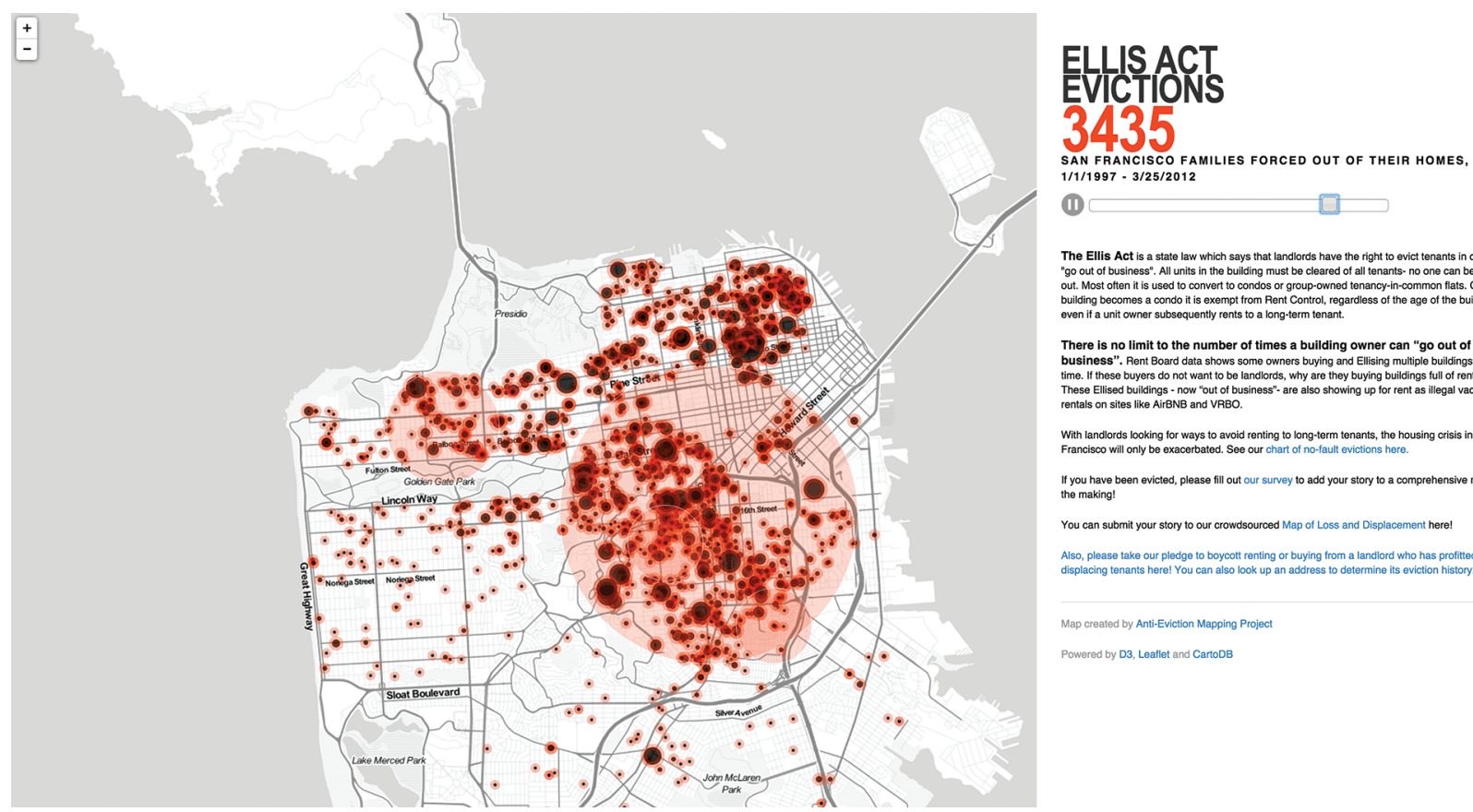

Ellis Act is a state law which says that landlords have the right to evict tenants in order to "go out of business". All units in the bulliding must be cleared of all tenants. no one can be singled out. Most often it is used to convert to condos or group-owned tonancy-in-common flats. Once a
building becomes a condo it is exempt trom Rent Control, regarcless of the age of the building, and buiding becomes a condo it is exxympt trom R Rent Control, regt
even if a unit owner subsequently rents to a long-term tenant.

There is no limit to the number of times a building owner can "go out of business". Rent Board data shows some owners buying and Ellising multiple buildings over
time. If these buyers do not want to be landlords, why are they buying buildings full of rental urits? These Ellised buildings - now "out of business"-are also showing up for rent as illegal vacation entals on sites like AirBNB and VRB

With lanclords looking tor ways to avoid renting to long-term tenants, the housing crisis in San only be exacerbated. See our chart of no-fault evictions here.

you have been evicted, please fill out our survey to add your story to a comprenensive map in the making!

You can submit your story to our croundon Also, please take our pledge to boycott renting or buying from a landlord who has profitted by
displacing tenants here! You can also look up an address to determine its eviction history.

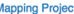

Fowered by DS. Leaflet end CartoDB

Figure 3. Interactive map (screen capture). From "Narratives of Displacement and Resistance" by Anti-Eviction Mapping Project (2015b). 
decades at once. This way, at a glance, we can evaluate the concentrations of evictions and determine that they tend to gather in the Mission District and other neighbourhoods further to the north and west.

Although the work done by the AEMP is useful and necessary, Erin McElroy, one of the project leads, notes that "dots on a map don't tell the whole story" (McElroy, Wojczuk \& Tirado 2015). The visualizations themselves as representations of a distribution of values show an overview of a phenomenon that necessarily reduces the individual events to data points where differences, apart from time and location, between data points are eliminated. The subjective dimension of each event is missing. The oral history map is an attempt to further our understanding of the impact of displacement by addressing this tendency of maps and visualizations to flatten differences and erase messy data (Pickles 2006: 349). In this map, two kinds of markers are used to represent the quantitative data and the qualitative data: firstly, red circle markers, whose size corresponds with the number of evictions, are used to represent building locations; secondly, blue circle markers are used to represent the profiles and stories of specific tenants. Users can hover over the red markers to see eviction information (i.e., building address, eviction type, number of units) or hover over the blue markers to see the tentant-interviewee profile. Clicking on the blue circle brings up a larger description panel with several media that can be played.

The stories gathered for the oral history map come mainly from three different processes. Some of the interviews come from volunteers reaching out to people affected by displacement and interviewing them for the sole purpose of the map. Others are gathered from a related event entitled Campfire: Eviction Ghost Stories and Other Housing Horrors, held the year before in San Francisco. Additionally, visitors to the site are offered the opportunity to add their own story through an online survey tool. Although organized through different initiatives, these activities offer similar opportunities for survivors of displacement to add their own testimony to the official record and history of the phenomenon.

From a network (i.e., actor-network) perspective, the collection of oral storytelling from people who have suffered and/or survived eviction constitutes a form of interessement. The voice, identity, and testimony is thus translated into a network that enrols actants and mobilizes these connections in a well-structured issuean attempt to significantly shift the frame of a matter of concern, for instance. Latour and Callon's concept of translation (Callon 1986; Latour \& Callon 1981) also includes several other processes that outline a specific form of power arrangement between, for instance, a researcher and a collectivity of human and non-human actants. Obligatory points of passage can place the researcher in a powerful position that manages the collective voice. Problematization frames an issue such that the researcher becomes indispensable. Enrolment brings the human actants into the network. Mobilization transports the issues in the network (via visual representations, etc.) to media, venues, and other networks that may serve the purposes of the researcher.

We can see how the AEMP has problematized the issue of unlawful evictions, set itself (and its parent organization, the San Francisco Tenants Union) as a nucleus of activity, enrolled storytellers, and mobilized the issue through their maps, etc. In this way, the AEMP loosely conforms to the model of interessement. The model specified by Latour and Callon, however, puts too much emphasis on the management role that translates a collectivity of actants into a larger actant. Gatekeeping and the stabilization of the network through the transfer of power from the collectivity to the manager may describe how particular forms of visualization or networks that use visualization may function, but for the purposes of understanding 
a critical visualization practice it is this very power dynamic that is questioned. ${ }^{6}$

Although there is a form of translation in the project that enrols storytellers into the project and mobilizes their experiences, the phases described by Latour and Callon do not exactly fit a critical visualization practice such as the AEMP. For instance, Erin McElroy, one of the members of the project, states that their aim is to work in a mutual-aid model that attempts to not just work for a community but to also share resources amongst community members (McElroy et al. 2015). However, if we apply the notion of assemblage to this multi-dimensional project we can see several features that help us understand how it operates beyond a frame of translation.

As part of an assemblage of enunciation these events help make incorporeal transformations, for there is an attendant form of empowerment wherein the storytellers are transformed from victims of displacement to survivors and sources of knowledge. This transformation from victim to survivor and knowledge bearer is reiterated through the oral history map itself. People are also designated as tenants and as humans with intrinsic value. They are incorporeally transformed from renters to community members.

It is useful also to consider how assemblages, especially those that comprise social movements, use expressive components. Manuel Delanda (2006), using the work of Charles Tilly, notes that the expressive capacities of assemblages are often in the service of establishing membership and solidarity, problematizing categorizations imposed by government, and communicating the magnitude of the movement (p. 59). In Latourian terms, these expressive capacities are also particularly powerful in the advocating of matters of concern. This is accomplished through the connection that is made to the issue, the project, and the larger community. This connection is sometimes framed as an act of solidarity or healing.
The data and stories, while representing a physical space, exist as digital or virtual spaces that are accessible from around the world through a computer and an Internet connection. Story collection can also work this way: there is a call-out and link on the oral history map that urges users to add their own story relating to displacement in the city. This design has particular capacities that allow the stories to travel fast and far-something that has been used by the AEMP to great effect. As an expressive component of an assemblage this facilitates not only the connection to other assemblages, but also the growth and continuing stability of the assemblage.

\section{Veridical and expressive visualization}

Territorialization of the assemblage's expressive capabilities can also contribute to the solidity and identity of the assemblage (DeLanda 2006: 59). In the present case, this can mean solidifying of the identity of the residents as survivors while locating this precisely at the heart of the neighbourhood heaviest-hit by gentrification. A tangible form and specifically-located instance of the map would have a set of characteristics, complimentary to the ones online, that would allow for preserving memory and honouring the stories of survivors. These are priorities which, we can imagine, propelled the Clarion Alley Mural Project in San Francisco's Mission District to ask the AEMP to create a mural about the work being done on displacement in the area (see Figure 4). This led to a physical mural which records the history of successful resistance and the struggles made by different tenants who fight eviction in the area-many of whom have successfully fought eviction attempts (Menchini 2015).

The mural was a collaborative effort by a group of volunteer artists and community members organized by the $A E M P$; it comprises a 20 -foot painted mural on 
Clarion Alley (Anti-Eviction Mapping Project 2015a). The Ellis Act Evictions map (which is on its way to becoming iconic through its repeated use across platforms and projects, and due to the recognizable form of the San Francisco Bay Area shoreline) is painted on the mural along with the portraits of several interviewees from the oral history map. The overview of the phenomenon is combined with the faces of the people which in turn represent personal stories. The personal stories are accessible through a local phone number posted on the mural. This is therefore also a locative media project wherein people who visit the mural can listen to the testimony and stand at the epicentre of the displacement crisis. Its location is also very important symbolically, according to Claudia Tirado, one of the storytellers, for it is very close to the local police station and the alley on which it is painted joins two major Bay Area streets: Valencia and Mission (McElroy et al. 2015). In addition, the Clarion Alley Mural Project has become an open-air public gallery as it is a site of a vast amount of murals that run the whole length of the alley on both sides. The site itself is a reminder of the ongoing grassroots creativity of the local residents and their connection to political resistance throughout the decades.

At the inauguration of the mural, McElroy reminded the attendees that the mapping project, although it started as a simple visualization, has grown to add layers of the story. The mural specifically also adds intersections within the current housing crisis in the SFBA, such as racial profiling by police, reduction in affordable housing, and violence against homeless people, which are important to understand as different dimensions of

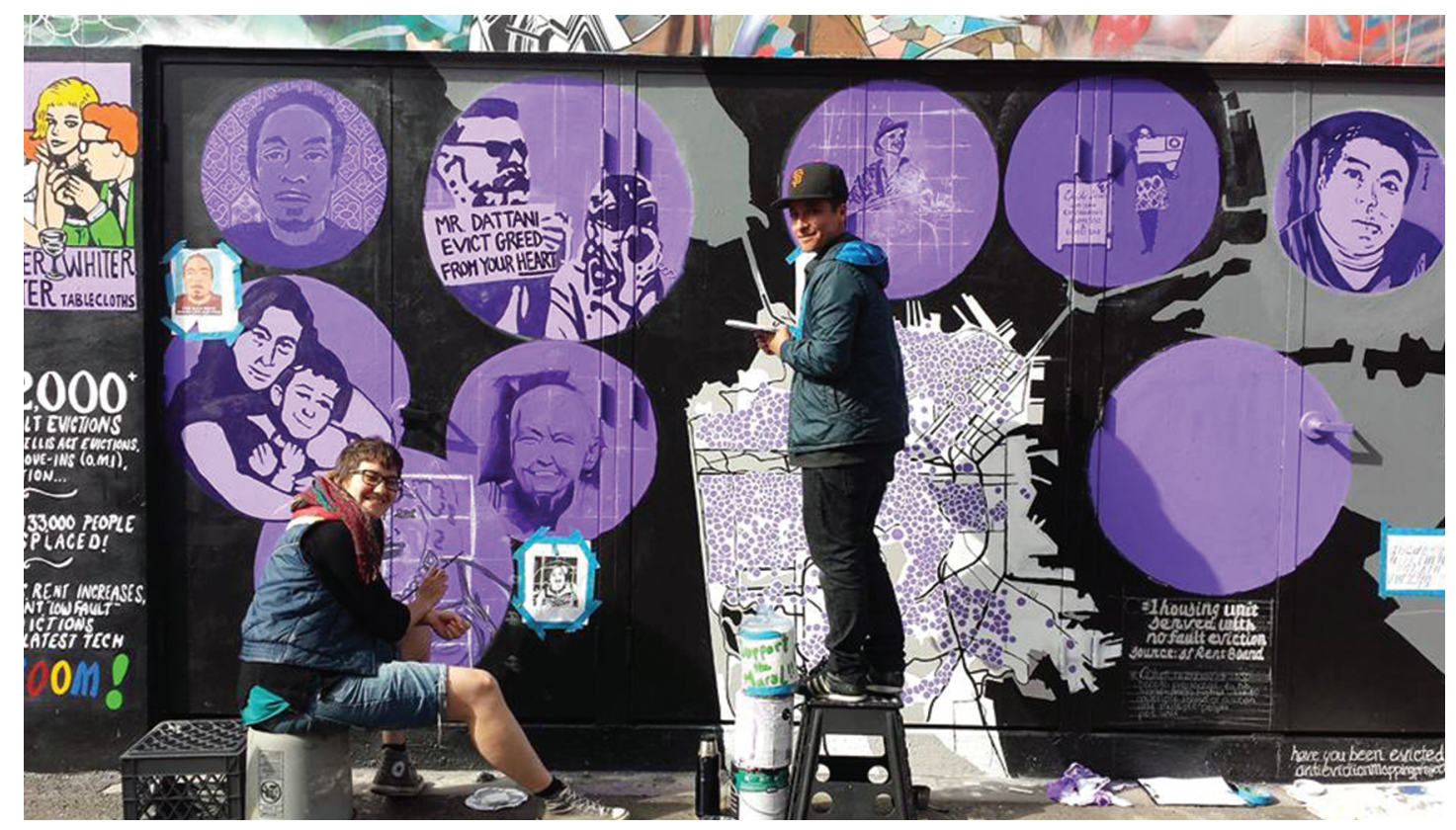

Figure 4. Volunteer painting mural. From "Clarion Alley Mural Project" by Anti-Eviction Mapping Project (2015a). 
a complex problem (Menchini 2015). Perhaps the most distinguishing marks are the circles with portraits of the storytellers; next is the familiar map (very similar to the evictions map) in the bottom centre. It is immediately readable as a story (or set of stories) about a place. Tirade also notes that the mural is particularly successful because it is logical and visually comprehensible. Murals, according to Tirado, can be very "artsy" but this mural "zeros in on the problem"; it is also "data-driven" but retains the emotion of "who is being displaced" (McElroy et al. 2015). This is an important and illustrative remark. As a teacher, as a parent, as a resident, and as a participant, Tirado finds the mural to function beyond artistic representation and rather as a visualization that has an indexical link to the events occurring in the area. The combination with portraits and oral testimony further adds to the evidence being presented but retains the emotional impact through the use of voice and human faces. It also reminds us of the promise of artistic visualization, and critical visualization practice more generally, that combines the veridical with the expressive in such a way that concerns are stabilized and cases strongly made, still the connections to the assemblage of human actants are acknowledged.

The active work in maintaining the assemblage and ultimately the community of workers, tenants, and advocates is also exemplified in the production of a zine. The stories from the map are transcribed and included in We Are Here: Oral Histories of San Francisco, produced by the AEMP. In zine form, the stories are circulated through more informal means that often involve face-to-face conversations and meetings at specific places (e.g., the mural or the SF Tenants Union office) and events (e.g., the mural inauguration). Rather than a limitation, this form of circulation helps define a community through a process of self-selection where access is granted to those within the community or who commit to participating in an event.

\section{Production of subjectivity and spatial understanding}

The oral storytelling performances (where stories were recorded and later included in the map) and the creation, unveiling, and everyday experiencing of the mural project, are events that play a role in the production of subjectivity. These are formalized spaces and times of reception of both stories and visualizations. They are intensified forms of what occurs at other times and places of reception-online, at the mural, on the phone, etc. As such they make more legible the ways in which an assemblage of enunciation is part of the production of subjectivity. These are processes that frame and reproduce the relationship between individual and community, and resident and neighbourhood or city.

From mapping evictions to showing patterns in transportation, to interviewing survivors to creating oral history maps, to hosting storytelling events to producing community-led murals, the diverse activities of the $A E M P$ have shown that mapping is a term that means more than placing markers on a two-dimensional representation of a territory. I suggest that the $A E M P$ works closer to a model of critical visualization practice. AEMP is a form of practice in that it instantiates an assemblage of enunciation aimed at resistance to and survival of gentrification and displacement. It is akin to Eades and Zheng's (2014) notion of a counter-mapping assemblage that attempts to bring together a heterogeneous network of people, objects, events, and places into a collectivity that tells a different story about a specific area.

Eades and Zheng (2014) note that "mapping is thus the process of producing and reproducing 'a spatial understanding' of a part of the world" (p. 81). In this general definition it is necessary to also include the use of graphic artifacts, systems, processes, and performances-especially in how they are used to connect with others. Eades and Zheng (2014) point to DeLanda's 
formulation that relations of exteriority are essential to how assemblages co-exist and interact with other assemblages (p. 90); specifically, they use this formulation to understand how a variety of platforms including publications and online mapping services are used by the Wemindji First Nation to relate their perspective to settler society and other Indigenous communities.

Similarly, the $A E M P$ works as an assemblage to resist displacement. It centres its activities around the notion of the map-partially because it began as a simple representation of the crisis. More importantly, the AEMP has continued mapping the stories, experiences, and facts of displacement on a history of San Francisco. In doing so, it has built an assemblage of enunciation that attempts to create counter-representations and through this enactment, an alternative production of subjectivity is instantiated.

\section{Conclusion}

I consider the Anti-Eviction Mapping Project to be an example of critical visualization practice precisely because it interrogates its own conditions of production and the way that who is represented is also affected by the representations. The challenge here has been to understand artifact or objects like the AEMP visualizations less as representations and more as a networks or assemblages. On the one hand, networks help us analyze the ways that evidence is ordered into a stabilized arrangement. On the other hand, assemblages help us understand AEMP as a creative practice that produces subjectivity. This project also illustrates how visualizations can work as processes, in an assemblage, that can take on different forms of expression that strengthen and proliferate the connections with other assemblages.

This overview demonstrates the suitability of using Latour's framework as a starting point to understand a larger picture of visualization practice. It also reveals the limits of that framework. To address these limits assemblage theory and specifically enunciation/expression were explored in order to extend the ways that a network-cum-assemblage can be used to look at critical visualization practice. Although it is beyond the scope of this article, visualization assemblage, as a framework, can be complimented by research that attends to the technical, cognitive, linguistic and semiotic aspects of information visualization and information design. The concept of visualization assemblage would be most useful as a meta strategy for bridging, for example, issues of visual language, semiotics of graphics, interactivity with issues of power, representation and participation.

\section{Submission date: 5 October, 2016 \\ Accepted date: 8 February, 2017}

\section{Notes}

1. This article contains portions from my doctoral dissertation, in Communication and Culture at York University, titled Visualization as Assemblage: How Modesty, Ethics, and Attachment Inform a Critical Design Practice which was defended in 2016.

2. A good introduction to Latour's concepts can be found in his Reassembling the Social: An Introduction to Actor-Network Theory.

3. A primary text on assemblage theory is Deleuze and Guattari's A Thousand Plateaus: Capitalism and Schizophrenia. For an authoritative introduction and expansion of Deleuze and Guattari's work please see Manuel Delanda's A New Philosophy of Society: Assemblage Theory and Social Complexity.

4. The AEMP website (www.antievictionmap.com) serves as a hub for providing access to the maps it has produced, oral stories it has compiled, and tools it has developed as well as the latest news regarding projects, solidarity efforts, and local news on policy, court decisions, etc. AEMP has produced over 30 maps which are available to visitors on its site. The site provides tools to fight eviction, a list of key individuals and organizations that contribute to the rise of hypergentrification. It also serves as a means for data gathering (e.g., several tools are available for 
users to contribute). From this site we are able to access several projects by the AEMP, including Ellis Act Evictions, the Narratives of Displacement Oral History Map, the Clarion Alley Mural Project, and the No Fault Evictions and Tech Bus Stops map.

5. Immutable mobiles refer to documents, maps, charts, images used by a researcher to relay important information about an event or thing to others readers, users, or researchers. Its relative stability makes it an authoritative document that can be a substitute for direct experience.

6. For another reformulation of interessement see Susan L. Star's (1990) concept of boundary objects which attempts to model it in non-hierarchical terms.

\section{References}

\section{AJ+. (2014). Mapping San Francisco's No-Fault Evictions} Since 1997. Retrieved from https://www.youtube.com/ watch?v=D3UPom9Ro4U

Anti-Eviction Mapping Project. (2013). No-Fault Evictions and Tech Bus Stops (San Francisco, 2011-2013). San Francisco, CA. Retrieved from http://www.antievictionmappingproject.net/ techbusevictions.html

Anti-Eviction Mapping Project. (2015a). Mural in Clarion Alley. Retrieved August 3, 2015, from http://www.antievictionmap. com/mural-in-clarion-alley

Anti-Eviction Mapping Project. (2015b). Narratives of Displacement and Resistance. Retrieved May 11, 2016, from http://www.antievictionmappingproject.net/narratives.html

Anti-Eviction Mapping Project. (n.d.-a). Ellis Act Evictions. Retrieved May 11, 2016, from http://www.antievictionmappingproject.net/ellis.html

Anti-Eviction Mapping Project. (n.d.-b). Tech Bus Stops and NoFault Evictions. Retrieved August 2, 2015, from http://www. antievictionmappingproject.net/techbusevictions.html

Callon, M. (1986). Some elements of a sociology of translation: domestication of the scallops and the fishermen of St. Brieuc Bay. In J. Law (Ed.), Power, Action and Belief: A New Sociology of Knowledge? (pp. 196-223). London, England: Routledge.

DeLanda, M. (2006). A New Philosophy of Society: Assemblage Theory and Social Complexity. London, England: Bloomsbury.
Deleuze, G. \& Guattari, F. (2004). A Thousand Plateaus: Capitalism and Schizophrenia. (B. Massumi, Trans.). London, England: Continuum.

Eades, G. \& Zheng, Y. (2014). Counter-mapping as assemblage. In B. Doolin, E. Lamprou, N. Mitev \& L. McLeod (Eds.), Information Systems and Global Assemblages: (Re)Configuring Actors, Artefacts, Organizations (Vol. 446, pp. 79-94). Berlin, Germany: Springer.

Latour, B. (1990). Drawing things together. In M. Lynch \& S. Woolgar (Eds.), Representation in Scientific Practice (pp. 19-68). Cambridge, MA: MIT Press.

Latour, B. (2004b). Why has critique run out of steam? From matters of fact to matters of concern. Critical Inquiry, 30, 225-248. doi: $10.1086 / 421123$

Latour, B. (2008). A cautious Prometheus? A few steps toward a philosophy of design (with special attention to Peter Sloterdijk). Presented at the Networks of Design, Design History Society, Falmouth, Cornwall, UK. Retrieved from http://www.bruno-latour.fr/sites/default/files/112-DESIGNCORNWALL-GB.pdf

Latour, B., November, V. \& Camacho-Hübner, E. (2010). Entering a risky territory: space in the age of digital navigation. Environment and Planning D: Society and Space, 28, 581-599. doi: 10.1068/d10409

Latour, B. \& Callon, M. (1981). Unscrewing the big Leviathan: how actors macro-structure reality and how sociologists help them to do so. In K. Knorr-Cetina \& A.V. Cicourel (Eds.), Advances in Social Theory and Methodology: Towards an Integration of Micro- and Macro-Sociologies (pp. 277-303). Boston, MA: Routledge \& Kegan Paul.

Lazzarato, M. (2014). Signs and Machines: Capitalism and the Production of Subjectivity. (J.D. Jordan, Trans.). Los Angeles, CA: Semiotext(e).

McElroy, E., Wojczuk, C. \& Tirado, C. (2015, May 19). Anti-Eviction Mapping Mural Project interview on Setting the Standards [Interview]. Retrieved from https://www.indybay.org/ newsitems/2015/05/19/18772469.php

Menchini, P. (2015). Mural on Clarion Alley: Narratives of Displacement \& Resistance 16 May 2015 [Video File]. Retrieved from https://vimeo.com/128097975

Müller, M. (2015). Assemblages and actor-networks: rethinking socio-material power, politics and space. Geography Compass, 9(1), 27-41. doi: 10.1111/gec3.12192 
Pickles, J. (2006). On the social lives of maps and the politics of diagrams: a story of power, seduction, and disappearance. Area, 38(3), 347-350. doi: 10.1111/j.1475-4762.2006.688_4.x

Stamen Design. (2012). The City from the Valley. Retrieved August 5, 2015, from http://stamen.com/zero1/

Star, S.L. (1990). The structure of ill-structured solutions: boundary objects and heterogeneous distributed problem solving. In L. Gasser \& M.N. Huhns (Eds.), Distributed Artificial Intelligence: vol. 2 (pp. 37-54). San Francisco, CA: Morgan Kaufmann Publishers Inc.

\section{About the author}

Patricio Dávila is a designer, artist and educator. He is Associate Professor at OCAD University and member of the OCADU Mobile Media Lab and Visual Analytics Lab. Patricio is director of Zero Lab, a research centre investigating the use of design and art practices for promoting environmental justice and imagining sustainable futures. His research focusses on how visualization can be framed as a critical design practice. In his creative practice he has created mobile applications, locative media, essay video, new media installations, and participatory projects. His current creative work focuses on information visualization through large-scale interactive public displays.

Email:pdavila@faculty.ocadu.ca 